\title{
The ongoing loss of historical material from institutions
}

\author{
Roger W. Byard ${ }^{1}$
}

Accepted: 14 October 2020 / Published online: 3 November 2020

(c) Springer Science+Business Media, LLC, part of Springer Nature 2020

In recent times there has been a trend to remove historical records and materials from museums and storage areas as these are perceived to be no longer a useful part of contemporary education and study. Empty white rooms with generic tables and regulation chairs have replaced older style conference rooms and libraries with their readily accessible departmental information. However, the perception that everything is now online can only be held by those who have never undertaken academic searches before or worked with students. Irreplaceable original research reports, out of print texts and theses and anatomical models have all ended up in rubbish skips in many institutions. The question to ask is: "Are we throwing the baby out with the bathwater?" i.e. are we losing vital data and materials in an attempt to remove what is currently perceived as not wanted or unnecessary?

When it is time to relocate and audit the storage areas of pathology museums specimens and materials are often uncovered that provide a valuable insight into diseases that may have become quite rare in contemporary practice. The fact that some of these conditions are undergoing a resurgence makes these materials even more valuable, as they can be used to directly teach us about processes that many of us no longer have practical experience of. Examples of museum material just from The University of Adelaide Pathology Collection that have had contemporary use by contributing significantly to recent review articles have involved cases of hydatid disease, syphilis and tuberculosis [1-4]. These reviews were only possible as the original autopsy reports going back over a century, pathology specimens and kodachrome ${ }^{\circledR}$ images have been retained.

Another good example of the potential significance of historical material involved original documents dealing with disease outbreaks amongst members of the Egyptian Expeditionary Force in the Middle East during World War I. These

Roger W. Byard

roger.byard@sa.gov.au

1 Adelaide Medical School Level 2 Helen Mayo Building North, The University of Adelaide, Frome Road,

South Australia 5005 Adelaide, Australia had been brought back to the University almost a century previously from Europe and the Middle East and were found in a storeroom that was being emptied. The material demonstrated graphically the toll that disease took on serving troops compared to trauma from gunfire during the first war. In fact, the ratio of casualties due to disease to those due to combat was more than 37:1 [5].

An excellent example of appropriate data preservation and storage involves the records of the Tasmanian Convict Department that are held in 522 volumes by the Tasmanian Archive and Heritage Office (TAHO) in Hobart, Tasmania. These represent the original records of the Tasmanian Convict Department from 1803 to 1893, are currently being digitized, and were placed on the UNESCO Memory of the World Register in 2007. They readily lend themselves to sociological, epidemiological and forensic pathology study of the convicts of eighteenth century Vandiemen's Land, sometimes producing data that has direct impact on modern classification systems [6].

The response of students to this type of material is also sometimes gratifying when they are confronted by something real and of historical value, rather than yet another bland screen of generic images. The response is akin to students who witness their first autopsy when they are at last able to see and experience the visceral reality of disease processes rather than simulated exercises from afar.

There appear to be two issues: firstly the belief that all that is old is somehow outdated and of no contemporary significance; the second is that only the most modern techniques and approaches have any validity in a teaching or research environment. It is puzzling to understand why this must be an "either/or situation". Surely a better approach would be careful auditing and evaluation of stored and historic material and then to have workshops to determine how best to incorporate all of this into the most useful model. This particularly applies to forensics, pathology and anatomical material. Unfortunately instructions to clear areas or tidy up may pre-empt this. A policy of preserving and integrating departmental resources rather than removing or 
dumping them would appear to be the most sensible, as once this material is gone it will never be retrievable.

\section{References}

1. Byard RW. An analysis of possible mechanisms of unexpected death occurring in hydatid disease (echinococcosis). J Forensic Sci. 2009;54:919-22.

2. Byard RW. Syphilis - cardiovascular manifestations of the great imitator. J Forensic Sci. 2018;63:1312-5.

3. Byard RW. Classical syphilitic lesions from the museum. Forensic Sci Med Pathol. 2019;15:309-13.
4. Stephenson L, Byard RW. An atlas overview of characteristic features of tuberculosis that may be encountered at autopsy. Forensic Sci Med Pathol. 2020;16:143-51.

5. Byard RW. Morbidity and mortality from infectious disease in the Egyptian Expeditionary Force (1916-1918). Forensic Sci Med Pathol. 2018;14:263-7.

6. Byard RW, Maxwell-Stewart H. Judicial murder-suicides in Van Diemen's Land. J Forensic Sci. 2018;63:1146-8.

Publisher's Note Springer Nature remains neutral with regard tojurisdictional claims in published maps and institutional affiliations. 